\title{
French and German Tourism in the Mediterranean - A Market Share Analysis
}

\author{
William Gatt $^{1 *}$ \& Joseph Falzon ${ }^{2}$ \\ ${ }^{1}$ Modelling \& Research Department, Central Bank of Malta, Malta \\ ${ }^{2}$ Department of Banking \& Finance, University of Malta, Malta \\ *Correspondence: William Gatt, Modelling \& Research Department, Central Bank of Malta, Pjazza \\ Kastilja, Valletta, VLT 1060, Malta. Tel: +356 22487923; E-mail: gattw@centralbankmalta.org \\ DOI: 10.12735/jotr.v1i1p21
}

\begin{abstract}
Tourism is an important economic sector for Mediterranean countries, and these compete for market share. In our study we look at the evaluation of market shares amongst a group of seven Mediterranean countries for both German and French tourists. Our data shows that these shares have changed significantly over the period 1963-2009. We utilise the Almost Ideal Demand System, a model grounded in economic theory, to understand what has driven these changes. The estimated own-price elasticities indicate the sensitivity of demand to price increases in each country, while cross-price elasticities shed light on the relative complementarity and substitutability of the holiday destinations. We find that while Spain was relatively unaffected by the development of the tourism market in countries such as Cyprus, Malta and Turkey, Italy lost significant market share, in part due to a relative loss of competitiveness. An innovation of this study is an assessment of the stability of the elasticity estimates over the sample. In line with other studies in this area, we highlight that the results of this study can serve as useful information for policymakers in the formulation of policies on tourism market development.
\end{abstract}

Keywords: tourism demand, almost ideal demand system, demand elasticities, Mediterranean countries

\section{Introduction}

\subsection{The Tourism Industry in the Mediterranean}

Countries in the Mediterranean Sea are touristic destinations in nature: they are blessed with many hours of sunshine, a warm climate, historic and artistic attractions, and an amusing nightlife. These countries also maintain unique cultures which introduces an element of heterogeneity in a tourist's experience. Therefore tourism tends to be an important economic sector in such countries, with significant direct and indirect contributions to Gross Domestic Product, especially in very small countries like Cyprus and Malta (see Figure 1).

Stakeholders in each country keep a close eye on the evolution of market shares, and seek to secure or indeed increase their country's share over time by implementing policies which make a holiday more competitive or unique. Demand elasticities play an important role in the development of marketing plans as they highlight how price sensitive a destination is, the element of substitutability with other destinations in close proximity and the extent to which changes in tourists' income impact the demand for a particular destination. Whereas one country might decide to focus on attracting a mass market with competitive packages, another might focus on higher-end niche marketing. 


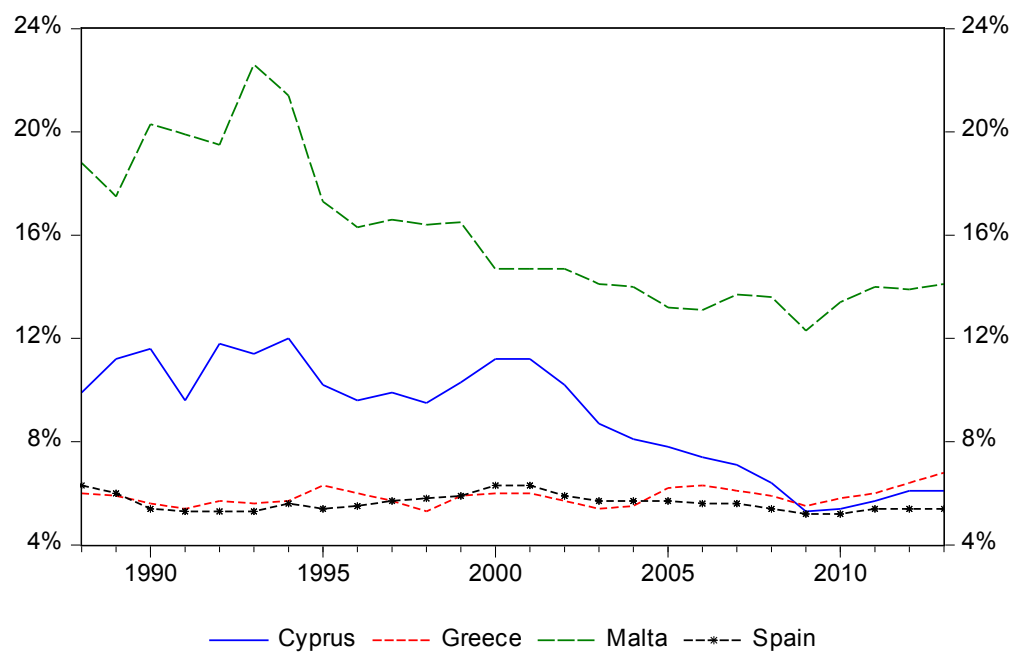

Figure 1: Travel and tourism direct contribution to

Source: World Travel and Tourism Council

The aim of this work is to analyse relative market shares in Mediterranean countries, and estimate the related tourism demand elasticities. In addition we address the standard assumption in the literature in that elasticities are treated as being fixed over many years. Such an issue can be answered given that the span of our analysis is large. Ultimately we use the estimates to explain the evolution of market shares in the different countries in our sample, and compare and contrast developments in the French and German markets.

\subsection{Measuring Demand Elasticities}

Although there are many tools that can be used to analyse and forecast tourism demand, the Almost Ideal Demand System (AIDS) developed in Deaton \& Muellbauer (1980) is particularly fit for estimating demand elasticities. The AIDS model is grounded in economic theory and hence is more powerful in terms of policy guidance compared with single-equation approaches (Durbarry \& Sinclair, 2003; Song \& Li, 2008). In the model the budget share of a product is expressed as a function of relative prices amongst other complementary or substitute products, and total expenditure within that product category:

$$
s_{i, t}=\alpha_{i}+\sum_{j} \gamma_{i, j} \log \left(\hat{p}_{j, t}\right)+\beta_{i} \log \left(\frac{X_{t}}{P_{t}}\right) \quad i, j=1, \ldots, n
$$

where $s_{i, t}$ is the budget share of good $i$ in the consumer's basket of goods at time $t, \hat{p}_{j, t}$ is the relative price of good $j, X_{t}$ is per capita total expenditure, and $P_{t}$ is a weighted price index across all competing products. $\alpha_{i}$ is the average share of product $i, \gamma_{i, j}$ measures the effect on the share of product $i$, subject to an increase in the relative price of product $j$, at constant expenditure levels. When $i=j$, this measure is the effect on the budget share of product $i$ subject to a change in its price. $\beta_{i}$ is the effect on the budget share of good $i$ given an increase in real expenditure per capita. However the parameters $\gamma_{i, j}$ and $\beta_{i}$ are not direct measures of elasticities; the latter can be obtained as the partial derivatives of equation 1 (see Hahn, 1994).

The AIDS model imposes the following restrictions on the parameters to satisfy the theoretical properties of a demand system:

$$
\begin{gathered}
\sum_{i} \gamma_{i, j}=\sum_{i} \beta_{i}=0 \\
\sum \alpha_{i}=1
\end{gathered}
$$




$$
\gamma_{i, j}=\gamma_{j, i} \quad \forall i, j
$$

Equation 2 ensures the homogeneity assumption, which states that a proportional change across all prices and expenditure does not alter the allocation of expenditure across the destinations. Equation 3 follows from restriction in equation 2 and refers to the adding-up restriction, such that that the sum of shares over all countries adds up to 1 in each period. The restriction in equation 4 imposes consistency in consumer choice across the whole system (Deaton \& Muellbauer, 1980).

In this study we expand on the coverage that has been employed in the literature by focusing on seven major Mediterranean holiday destinations: Cyprus, Greece, Italy, Malta, Portugal, Spain and Turkey. We estimated demand elasticities for German and French tourists visiting these countries over the period 1963 to 2009. Our prior expectations were for Spain to have held a dominant position as a touristic hub, such that demand for its holiday experience was both price and expenditure inelastic, and relatively unaffected by developments in other competing destinations. Similarly we expected Turkey to have won over market share over time, especially due to the devaluation in its currency that took place following the reforms of the 1980s.

\subsection{The Evolution of the Mediterranean Tourism Industry}

Tourism in the Mediterranean has been for a long time typically associated with the 'sun, sea and food" type of holiday, but "cultural and heritage-based" destinations such as Greece and Italy also form part of the Mediterranean tourism package on offer (Manera, Segreto \& Pohl, 2009, p. 4). Over time, however, consumer demands and expectations evolved to a more complex mix of elements within the same holiday. This gave rise to other variants of tourism, such as ecotourism, academic tourism and medical tourism. This development is largely attributed to the general decline in travel costs over the years, due to both travel regulatory changes ${ }^{1}$ as well as the adoption of the jet engine for passenger flights such that "speed made luxury unnecessary" (Lyth, 2009, p.18). This new environment gave rise to the phenomenon titled 'mass tourism', during which the tourism industry experienced a large boom. Indeed the countries in our sample experienced a substantial increase in tourist arrivals during the 1980s and 1990s.

However Portugal and Greece did not adopt entirely the model of cheap tourism for the masses, but through market segmentation they also targeted 'elite' tourism and managed to maximise revenue per tourist for a significant number of years (Câmara, 2009). Amongst the countries in our sample, Italy appears to have fared the worst in terms of tourist arrivals and market share. We believe this is because the country has been for a long time a traditional destination, and therefore a saturated destination, which lost market share in relative terms when other destinations increased their tourism marketing effort. The growth in demand also encouraged investment in resorts such as those of Ayia Napa, Limassol, and Paphos in Cyprus (Sharpley, 2003). Indeed efforts to boost supply in resorts across the Mediterranean in the early 1990s resulted in a shift of market control from hoteliers to tour operators; indeed we link this development to the decline in the estimated price elasticity in a number of countries, which we present in section 4.2.

During the period of analysis French and German tourism in the Mediterranean was also considered as being important for the supply of foreign exchange which was needed to finance imports. This reaffirms the important role tourism had for the economic development and growth in Mediterranean countries. In Portugal, for instance, Government intervention in the form of loans and incentives to attract foreign direct investment helped to boost economic growth (Câmara, 2009).

\footnotetext{
${ }^{1}$ Namely the deregulation effort in the aviation industry in Europe which led to an increase in airline competition.
} 


\section{Literature Review}

An analysis of the literature reveals that most studies focused on tourism flows originating from Britain, with fewer authors expanding the analysis to other countries, such as Germany and France as in this study. The main findings of papers that include the countries of interest are summarised below. An influential study, and indeed one of the earliest, on the application of the AIDS model to tourism is Syriopoulos \& Sinclair (1993), who investigate the allocation of tourism expenditure by residents of the United Kingdom (UK), France, West Germany, Sweden and the United States of America (USA) between Spain, Portugal, Italy, Greece and Turkey during 1960 and 1987. The authors report expenditure, (uncompensated and compensated) own-price and cross-price elasticities for these destinations for each origin country. The expenditure elasticities indicated that Mediterranean tourism was a normal good during the period, and Swedish and French tourists had the highest expenditure elasticities.

Turkey, Portugal and Greece where found to be destinations which are highly sensitive to fluctuations in tourism expenditure. In addition tourists from Sweden, the UK and Germany were very price-sensitive, though tourism from all origin countries in Portugal in particular tended to be highly sensitive to prices. They also report Greece-Spain, Greece-Portugal, Spain-Portugal and Italy-Turkey as substitute destinations, while the pairs Greece-Italy, Spain-Turkey, Portugal-Italy and Spain-Italy were characterised as complementary holiday destinations.

In another seminal study Papatheodorou (1999) analysed tourism from France, the UK and West Germany to Greece, Italy, Portugal, Spain, Turkey and Yugoslavia for the period 1958 to 1990. It was observed that the tourism shares exhibited substantial changes over just under four decades, with some countries consistently gaining market share to the loss of others. This observation motivated the introduction of a logarithmic trend to the basic AIDS model to capture changes in tastes over the Mediterranean holiday destinations.

The estimation resulted in statistically significant expenditure elasticities for Greece, Italy, Spain and Turkey, as opposed to non-significant values for Portugal and Yugoslavia. The author attributes this result to the "highly developed tourism infrastructure [... and] diversified product to satisfy different groups of tourists" Papatheodorou (1999, p. 626). The insignificant expenditure elasticities of Portugal and Yugoslavia, two peripheral countries, indicated a tourist product of low quality such that demand for it fell as tourists became richer. These results contrast those documented in Syriopoulos and Sinclair (1993).

The estimated own-price elasticities do not exhibit any particular pattern, however Portugal tended to be the most price-sensitive destination while demand for Yugoslavia tended to be unaffected by changes in relative price. ${ }^{2}$ An analysis of the cross-price elasticities highlights the substitutability of Spain and Portugal, owing to their proximity and perceived similarity in culture the so-called characteristics effect. Meanwhile Greece and Turkey were regarded as complimentary destinations, possibly owing to the distance between these countries relative to the distance to the source countries, prompting tourists to visit both during the same trip - the voyage effect (Papatheodorou, 1999). In other studies, which analyse tourism flows from the United Kingdom, De Mello, Pack and Sinclair (2002), and Mangion, Durbarry and Sinclair (2005) use France, Spain and Portugal, and Malta, Cyprus and Spain respectively as destination countries.

The standard, 'static' AIDS model has also been estimated in a dynamic form, in the form of an error-correction model, in Durbarry \& Sinclair (2003), Li, Song \& Witt (2004) and Mangion et al. (2005). The authors claim that it is not only long run elasticities which are important for understanding tourism demand but also the short run dynamics of the system. This is especially the

\footnotetext{
${ }^{2}$ It is argued that due to the socialist regime at the time, the CPI may not have been an ideal measure of cost.
} 
case if the model is to be used for forecasting (Li et al., 2004). Durbarry \& Sinclair (2003) apply the dynamic specification of the AIDS model to study the French tourism demand in Italy, Spain and the United Kingdom for the period 1968-1999. It resulted that the short run parameters were not statistically significant, and thus the system was reduced to the static, long run specification. Ownprice elasticity estimates for Spain and Italy were very similar, at -1.80 and -1.75 respectively. Meanwhile it appears that French tourists considered these destinations as substitute holidays to some extent, and Italy tended to gain slightly more market share than Spain when French tourism expenditure increased. Cortés-Jiménez, Durbarry \& Pulina (2009) also estimate a dynamic AIDS model in an error-correction framework for demand by Italian tourists. The authors use monthly data for this purpose, and confirm the finding of Li et al., (2004) that the dynamic version of the AIDS model is superior to the static, long run version in terms of forecast accuracy.

Modelling time variation in an AIDS model context is relatively new; but some attempts are Li, Wong, Song \& Witt (2006) and Mangion, Cooper, Cortés-Jiménez and Durbarry (2012). Both studies show that time variation is present in elasticity estimates; providing further scope for the analysis in section 4.2. The AIDS model has also been applied for regions outside of the Mediterranean. Divisekera (2003) analyses tourism elasticities between the United Kingdom, Australia, New Zealand and the United states, using all countries as both destination and source countries. Other, more recent examples of tourism elasticity estimates can be found in Koike \& Yoshino (2013) and Athanasopoulos, Deng, Li, \& Song (2014), who apply the model for tourists originating from Japan and Australia respectively.

Table 1. Empirical elasticity estimates

\begin{tabular}{|c|c|c|c|c|c|}
\hline & \multicolumn{5}{|c|}{ Destination } \\
\hline & Greece & Italy & Portugal & Spain & Turkey \\
\hline \multicolumn{6}{|c|}{ Origin: France } \\
\hline \multicolumn{6}{|c|}{ Own price elasticity } \\
\hline $\mathrm{P}$ & -1.02 & -1.54 & -2.28 & -1.58 & -1.24 \\
\hline SS & -0.27 & -0.95 & -1.90 & -1.17 & -0.51 \\
\hline DS & - & -1.75 & - & -1.80 & - \\
\hline \multicolumn{6}{|l|}{ Expenditure } \\
\hline \multicolumn{6}{|l|}{ Elasticity } \\
\hline $\mathrm{P}$ & 1.05 & 0.92 & 0.37 & 1.25 & 0.66 \\
\hline SS & 1.26 & 0.85 & 1.45 & 1.08 & 2.40 \\
\hline DS & - & 1.25 & - & 0.84 & - \\
\hline \multicolumn{6}{|c|}{ Origin: Germany } \\
\hline \multicolumn{6}{|c|}{ Own price elasticity } \\
\hline $\mathrm{P}$ & -1.45 & -1.24 & -2.31 & -1.33 & -1.11 \\
\hline SS & -2.03 & -0.8 & -1.35 & -1.82 & -1.67 \\
\hline \multicolumn{6}{|l|}{ Expenditure } \\
\hline \multicolumn{6}{|l|}{ Elasticity } \\
\hline $\mathrm{P}$ & 1.38 & 1.42 & -0.24 & 0.99 & 0.40 \\
\hline SS & 1.07 & 1.02 & 1.01 & 0.81 & 1.73 \\
\hline \multirow{2}{*}{\multicolumn{3}{|c|}{$\begin{array}{l}\text { Legend: } \\
\text { P - Papatheodorou (1999) }\end{array}$}} & \multicolumn{3}{|c|}{ Sample period } \\
\hline & & & $1957-1990$ & & \\
\hline \multicolumn{3}{|c|}{ SS - Syriopoulos \& Sinclair (1993) } & \multirow{2}{*}{\multicolumn{3}{|c|}{$\begin{array}{l}1960-1987 \\
1968-1999\end{array}$}} \\
\hline \multicolumn{3}{|c|}{ DS - Durbarry \& Sinclair (2003) } & & & \\
\hline
\end{tabular}

For the purpose of summarizing the key results in the literature which are relevant to the estimates of this paper, Table 1 compares the elasticity estimates across different studies for the countries that are studied in this paper. 


\section{Data and Methodology}

The AIDS model discussed in section 1 specifies the budget share of a product as a function of its own and relative price of other products, as well as total expenditure on that product category. In the context of tourism demand the budget share is typically expressed as the share of tourist arrivals or tourist bed-nights from a source country to the various destinations included in the study. Relative prices are exchange-rate adjusted relative consumer price indices, and real expenditure per capita is total expenditure amongst all the destination countries in terms of the number of tourists from the source country, deflated by an aggregate price index.

We follow closely the methodology in Papatheodorou (1999) such that total tourism expenditure for each destination was calculated by multiplying total tourism receipts in country $i$ by the fraction of tourist arrivals from the source country over all tourist arrivals in country $i$. Tourist arrivals data in each country from France and Germany was obtained from the OECD's Tourism Policy and International Tourism in OECD Member Countries, various statistical institutes, and the Malta Tourism Authority. Data on exchange rates was sourced from the IMF's International Financial Statistics (IFS), the European Central Bank and Eurostat, and data for travel export receipts of the destination countries was obtained from the IMF's Balance of Payment Statistics. Some of the data for tourist arrivals, travel export receipts and exchange rates came from the same data set as that used in Papatheodorou (1999).

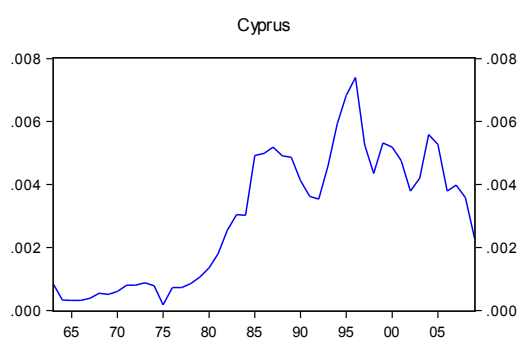

Malta

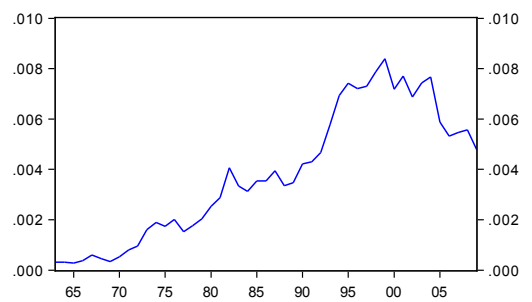

Greece

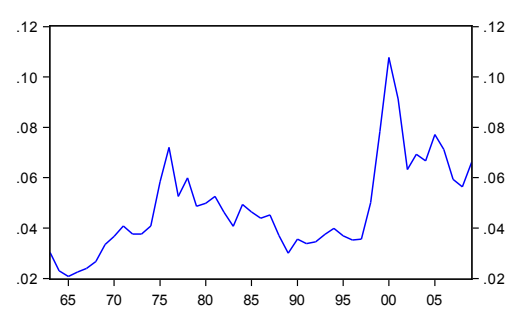

Portugal

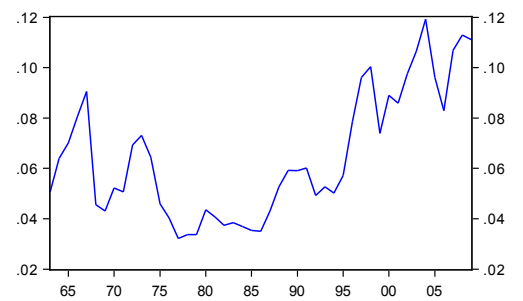

Turkey

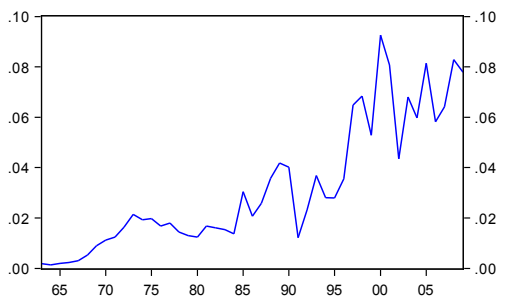

Italy

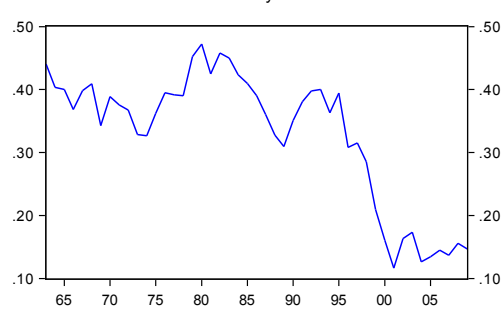

Spain

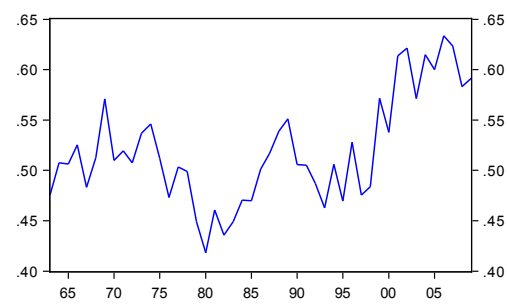

Figure 2. Expenditure shares of French tourists

Data for consumer price indices was obtained from the IFS and the Deutsche Bundesbank. We list the caveat that owing to the long span of the data an element of measurement error is present in the variables that we use to estimate the model. There is the possibility of changes in the data collection methodology over the years, as well as the splicing of data from different sources. 
Furthermore some missing observations had to be imputed using simple interpolation methods. Nevertheless we believe that given the long data set that we used these potential measurement errors do not impact the conclusions of this study in any significant way. We proceed at looking at some of the variables used in the estimation of the model.

Figures 2 and 3 show the shares of each destination country from French and German tourists respectively during the period 1963-2009. The diagrams share the same story; Italy started off with high shares in both source markets in the 1960s (around 60\% from France and 40\% from Germany), only to lose these over time to Spain, Portugal, Turkey, Cyprus and Malta by the late 1990s. Greece managed to double its share in the German market, from around 5\% up to the late 1990 s to $10 \%$ thereafter. This data confirms part of our prior expectations discussed in section 1; Spain and Turkey were indeed able to secure a strong position in the tourism market from both France and Germany.
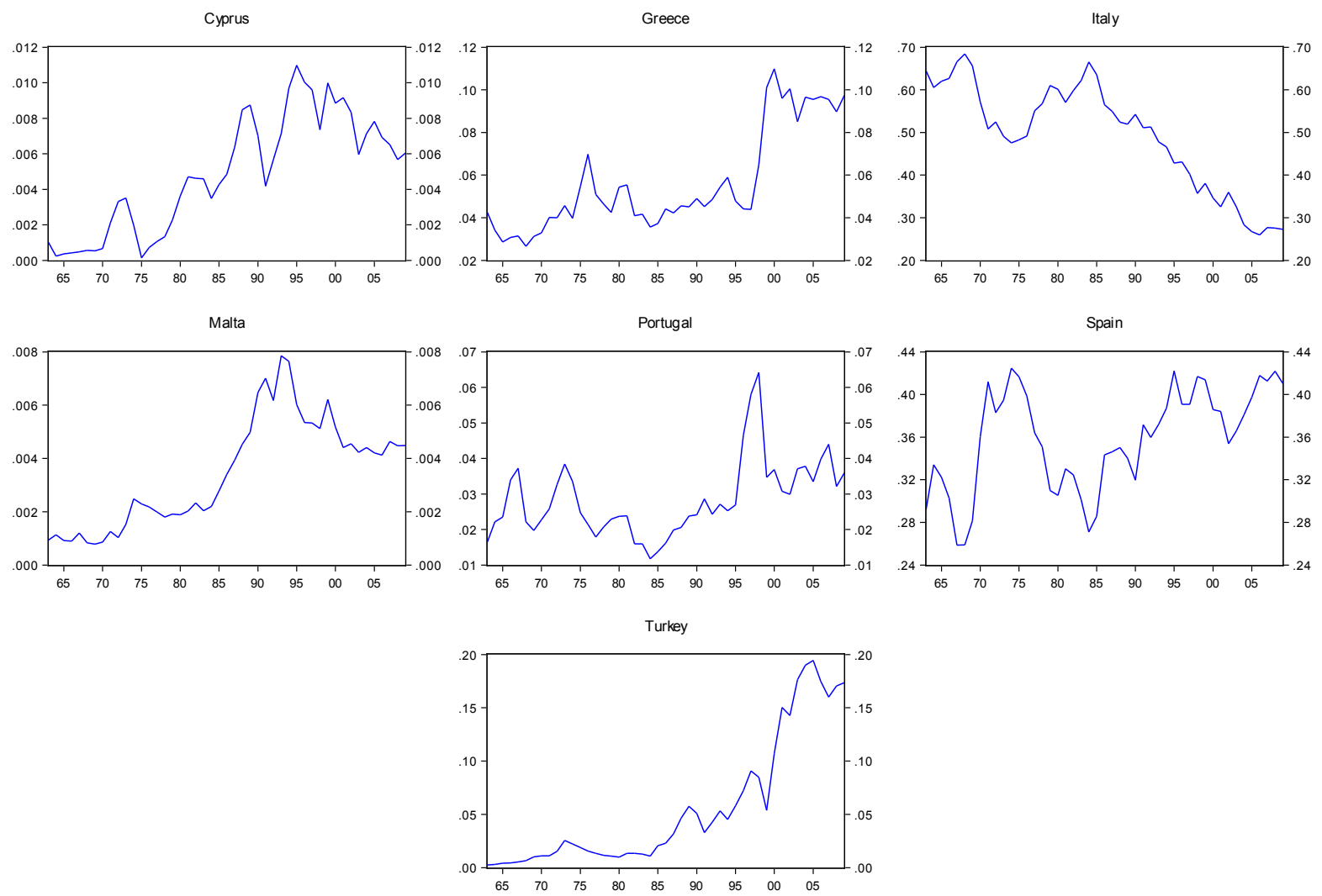

Figure 3. Expenditure shares of German tourists

The next variable of interest is the exchange-rate adjusted relative price index, and we follow De Mello et al. (2002) and Mangion et al. (2012) in constructing this variable. Figures 4 and 5 show the exchange-rate adjusted relative price indices for the seven destination countries with respect to the two source countries, using 1963 as the base year. It is interesting to note the impact of the strong devaluation of the Cypriot, Maltese and Turkish currencies on the effective price during most of the sample period.

The final variable that is required is a measure of real tourism expenditure per capita. We follow Papatheodorou (1999) by summing tourism expenditure across all countries to arrive at total expenditure, and use the sum of tourist arrivals across the destination countries to obtain a measure of the relevant population. Furthermore we follow the standard approach in the literature and deflate 
expenditure per capita by an aggregate price index for all destination countries using Stone's linear approximation (Stone, 1954). Figure 6 shows that real tourism expenditure per capita rose significantly over four decades across the countries we analysed.

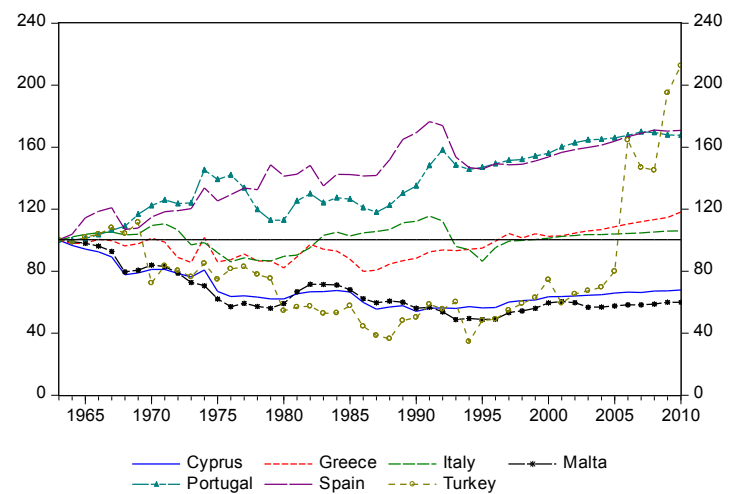

Figure 4. Relative Prices for French Tourists $(1963=100)$

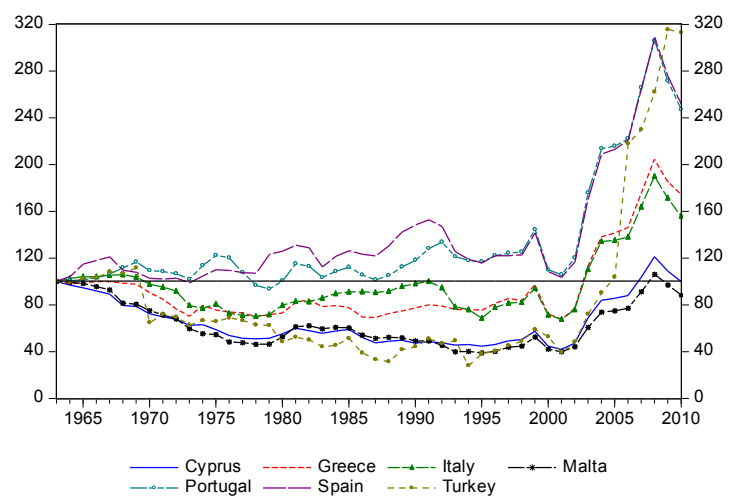

Figure 5. Relative prices for German tourists $(1963=100)$

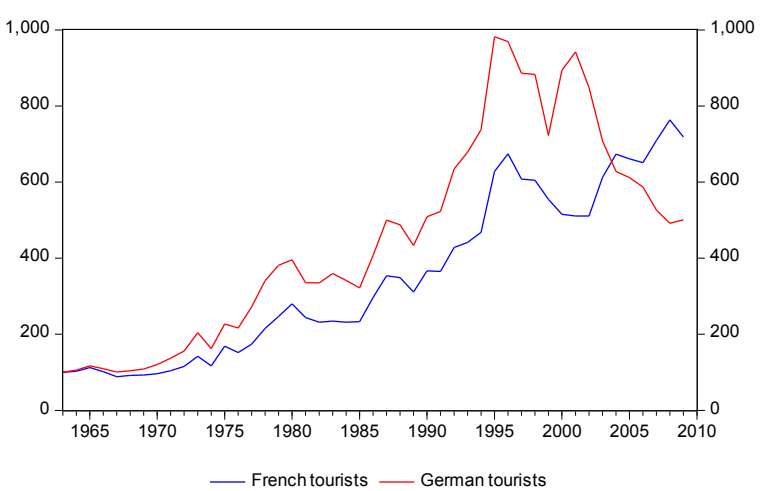

Figure 6. Real tourism expenditure per capita $(1963=100)$

Following Papatheodorou (1999) we augmented the system with a logarithmic time trend starting from 1963, and imposed the restriction that the coefficients related to this variable sum up to zero over the equations. Given that in a system such as the AIDS model the residuals equations can be correlated, we estimated all models using the Seemingly Unrelated Regression (SUR) 
estimator, and dropped one equation from the system to avoid obtaining a singular covariance matrix. The parameters of the omitted equation were then recovered using the adding-up restrictions. Our strategy involved estimating the model for both France and Germany twice, once over the full sample period to obtain 'average' values for the coefficients, and another by implementing an algorithm to estimate the system recursively, starting from 1963-1980 and adding one more observation in each iteration. At each iteration we save the vector of coefficients from the system such that we build a time series for each coefficient in the model. The recursive estimates were used to assess the stability of the estimates across time, as we expected some elasticity estimates to vary over time due to the structural changes that most economies had gone through during the period. ${ }^{3}$

Both the 'average' and recursive coefficients were used to estimate the (uncompensated) ownprice, cross-price and expenditure elasticities using the formulas detailed in Hahn (1994). We use the last year in the estimation as the base year in constructing the elasticities, as in Papatheodorou (1999).

\section{Results}

\subsection{Full Sample Estimates}

We proceed by presenting the results of the full sample estimation first before analysing the stability of the estimated parameters. Following our discussion above, we first estimated the model by dropping the equation for Turkey. As a type of robustness check we repeated the experiment by dropping the equation for Malta. ${ }^{4}$ Although most elasticity estimates are quantitatively very similar across estimations, some tended to differ especially when the destination tended to have a very low average share. ${ }^{5}$ We decided to present the results of the model which omits the equation for Turkey since it gave more economically plausible results for Malta.

The own-price elasticities in Table 2 are all negative as expected, such that a $1 \%$ increase in prices in a destination is followed by an $x \%$ drop in its tourism demand. Cyprus and Malta emerge as very price-sensitive destinations, although the elasticities are not statistically significant in the French market, not even at the $10 \%$ level of significance. Meanwhile Turkey registered as a priceinelastic destination in both markets. ${ }^{6}$ Italy appears to have been price-elastic only for the French market, while Greece, Portugal and Spain tended to be similar in that they registered elasticities between -1.3 and -1.5 . These results tend to rest within the estimates produced in other studies, which have been reproduced in Table 1 above. ${ }^{7}$

${ }^{3}$ This is done in the spirit of Li et al., (2006) and Mangion et al., (2012), who find evidence for variation in elasticity estimates.

${ }^{4}$ Under some assumptions the parameter estimates should theoretically be invariant to the equation that is dropped (Syriopoulos \& Sinclair, 1993; Papatheodorou, 1999; De Mello et al., 2002), however this property is typically assumed rather than tested in applied work.

${ }^{5}$ In fact the own-price elasticities for Malta differ the most, although the main conclusion remains unchanged. We also observed the small-share property to affect significantly the recursive estimates which we present in section 3.2.

${ }^{6}$ These figures are almost identical to those estimated from the alternate estimation, and in which these results are highly statistically significant.

${ }^{7}$ As discussed in Li et al., (2004) it is a common occurrence for estimates to differ somewhat between studies. 
Table 2. Own-price elasticities

\begin{tabular}{lccccccc}
\hline & Cyprus & Greece & Italy & Malta & Portugal & Spain & Turkey \\
\hline \multirow{6}{*}{ France } & -3.85 & -1.27 & -1.51 & -2.84 & -1.29 & -1.51 & -0.84 \\
& $(-0.77)$ & $(-1.77)$ & $(-5.94)$ & $(-0.63)$ & $(-3.08)$ & $(-10.15)$ & \\
& & & & & & & \\
Germany & -5.24 & -1.39 & -0.39 & -10.08 & -1.29 & -1.35 & -0.57 \\
& $(-1.71)$ & $(-2.27)$ & $(-2.29)$ & $(-2.03)$ & $(-1.35)$ & $(-6.44)$ & \\
& & & & & & & \\
\hline
\end{tabular}

Note: numbers in brackets are $t$-statistics

Turning to the expenditure elasticities in Table 3, Malta and Cyprus again tended to be the most sensitive to changes in tourist expenditure, although those for the German market are not statistically different from zero. On the other hand Italy was the least sensitive to changes in expenditure in both markets. Almost all other countries had unitary or greater than unitary expenditure elasticities, such that they benefitted from a proportionally equivalent or higher increase in demand as expenditure rose. This could explain why not only Italy failed to keep its high market shares, but also why, with increasing affluence, tourists opted for potentially more expensive means of transportation to visit countries further away.

Table 3. Expenditure elasticities

\begin{tabular}{lccccccc}
\hline & Cyprus & Greece & Italy & Malta & Portugal & Spain & Turkey \\
\hline \multirow{2}{*}{ France } & 1.49 & 1.03 & 0.31 & 1.47 & 1.28 & 1.08 & 1.25 \\
& $(2.12)$ & $(6.96)$ & $(3.90)$ & $(1.84)$ & $(10.11)$ & $(31.31)$ & \\
Germany & 0.98 & 1.30 & 0.63 & 2.59 & 0.89 & 1.07 & 1.22 \\
& $(1.40)$ & $(9.45)$ & $(11.25)$ & $(1.46)$ & $(2.82)$ & $(20.25)$ & \\
& & & & & & & \\
\hline
\end{tabular}

Note: numbers in brackets are $t$-statistics

The cross-price elasticities in Tables 4 and 5 reveal that French tourists were relatively unaffected by changes in prices in the whole 'batch' of Mediterranean countries when taking a decision to visit a particular country, as most estimates are not statistically significant. To the contrary, German tourists tended to be affected by price dynamics across the destination countries. Both sets of tourists considered Spain-Italy and Malta-Italy as substitutes, and Italy-Turkey and Italy-Greece as complements. ${ }^{8}$ Furthermore German tourists considered Spain-Cyprus, SpainPortugal, Spain-Turkey and Greece-Turkey as substitute destinations.

Conversely the pairings Italy-Cyprus, Italy-Portugal and Spain-Malta were considered as complimentary destinations by German tourists. The strongest relationships between prices and

\footnotetext{
${ }^{8}$ Positive cross-price elasticities imply an element of substitution, such that if the price of one destination rises, demand in the alternate destination rises. Negative cross-price elasticities imply that two countries suffer a drop in demand if prices in one of them rise.
} 
demand, both positive and negative, were price changes in Italy and Spain on both Malta and Cyprus, with the elasticities relating to Maltese tourism being particularly large. On the other hand the model confirms our prior beliefs that Spain held a dominant position over time and was largely unaffected by developments in other countries, while Turkey as an emerging economy, managed to market itself perhaps as an exotic holiday destination, thus putting it in a category of its own.

Table 4. Cross-price elasticities - French market

\begin{tabular}{|c|c|c|c|c|c|c|c|}
\hline & Cyprus & Greece & Italy & Malta & Portugal & Spain & Turkey \\
\hline \multirow[t]{2}{*}{ Cyprus } & & 0.14 & -0.07 & 0.21 & 0.00 & 0.01 & -0.04 \\
\hline & & $(0.52)$ & $(-1.85)$ & $(0.06)$ & $(0.02)$ & $(0.75)$ & \\
\hline \multirow[t]{2}{*}{ Greece } & 4.06 & & -0.53 & 6.05 & 0.51 & -0.01 & 0.05 \\
\hline & $(0.94)$ & & $(-5.60)$ & $(1.28)$ & (1.43) & $(-0.12)$ & \\
\hline \multirow[t]{2}{*}{ Italy } & -4.80 & -1.25 & & 3.25 & -0.21 & 0.44 & -1.11 \\
\hline & $(-1.17)$ & $(-1.98)$ & & $(0.56)$ & $(-0.44)$ & $(3.26)$ & \\
\hline \multirow[t]{2}{*}{ Malta } & 0.43 & 0.44 & 0.11 & & -0.05 & -0.05 & -0.05 \\
\hline & $(0.11)$ & (1.18) & (1.67) & & $(-0.19)$ & $(-1.36)$ & \\
\hline \multirow[t]{2}{*}{ Portugal } & 0.20 & 0.88 & -0.04 & -1.17 & & -0.05 & 0.23 \\
\hline & $(0.06)$ & $(1.83)$ & $(-0.43)$ & $(-0.26)$ & & $(-1.01)$ & \\
\hline \multirow[t]{2}{*}{ Spain } & 3.68 & -0.03 & 2.25 & -6.21 & -0.41 & & 0.50 \\
\hline & (0.99) & $(-0.05)$ & $(9.49)$ & $(-1.19)$ & $(-0.89)$ & & \\
\hline Turkey & -1.21 & 0.07 & -0.52 & -0.76 & 0.16 & 0.08 & \\
\hline
\end{tabular}

Note: numbers in brackets are $t$-statistics

Table 5. Cross-price elasticities - German market

\begin{tabular}{lccccccc}
\hline & Cyprus & Greece & Italy & Malta & Portugal & Spain & Turkey \\
\hline Cyprus & & 0.09 & -0.15 & 4.32 & 0.35 & 0.07 & -0.02 \\
& & $(0.39)$ & $(-5.80)$ & $(1.21)$ & $(0.91)$ & $(2.40)$ & \\
Greece & 1.47 & & -0.12 & 5.91 & 1.09 & -0.09 & 0.20 \\
& $(0.55)$ & & $(-1.87)$ & $(1.13)$ & $(1.34)$ & $(-1.36)$ & \\
Italy & -6.69 & -0.53 & & 19.17 & -2.19 & 0.22 & -0.99 \\
& $(-2.65)$ & $(-1.00)$ & & $(2.96)$ & $(-2.08)$ & $(1.12)$ & \\
Malta & 3.21 & 0.27 & 0.33 & & -0.79 & -0.17 & 0.01 \\
& $(1.27)$ & $(0.87)$ & $(7.24)$ & & $(-1.31)$ & $(-3.20)$ & \\
Portugal & 2.07 & 0.39 & -0.28 & -6.40 & & 0.16 & 0.00 \\
& $(0.93)$ & $(0.96)$ & $(-4.60)$ & $(-1.28)$ & & $(2.09)$ & \\
Spain & 4.74 & -0.48 & 0.51 & -15.80 & 1.92 & & 0.15 \\
& $(2.12)$ & $(-1.07)$ & $(3.34)$ & $(-2.79)$ & $(1.87)$ & & \\
Turkey & -0.55 & 0.36 & -0.54 & 0.29 & 0.02 & 0.09 & \\
& & & & & & &
\end{tabular}

Note: numbers in brackets are $t$-statistics 


\subsection{Recursive Estimates}

In figures 7 and 8 we show recursive estimates of these elasticities over time. The algorithm we employ starts from an estimation using data from 1963 to 1980 and subsequently adds another observation and re-estimates the system, until all the data points are included. Recursive estimates are typically used to assess the stability of a model's parameters. Our estimates highlight the variability of consumers' behaviour over time, and thus we argue that the full sample 'average' elasticities should be interpreted with this observation in mind for some countries.

We notice that for countries with very small shares the elasticities tended to be very high at the start of the exercise, after which they converged to more reasonable levels. We attribute this phenomenon to the very small share in the early part of the same. We also notice similar behaviour across the two source countries in the sense that elasticities tended to co-move in most countries. We interpret changes in the elasticities over time in the context of the changing environment in tourism, as discussed in section 1.3.

We note that Italy experienced a decline in its price elasticity from German tourists in absolute terms, as well as a decline in its expenditure elasticities from both French and German markets. This reflects the narration above in that Italy became a saturated market over time and thus an increase in tourism resulted in a small increase in tourist arrivals relative to other destinations, hence leading to a loss of market share. Spain on the other hand experienced low changes to its price and expenditure elasticities in both markets, and experienced a gradual increase in its expenditure elasticity over time, which explain why market shares increased after the mid-1980s. During this period the price elasticity of demand in Greece and Portugal also fell gradually in absolute terms, implying that tourism became less sensitive to price developments. This could be a result of the market segmentation discussed above; as 'elite' tourism gained traction.
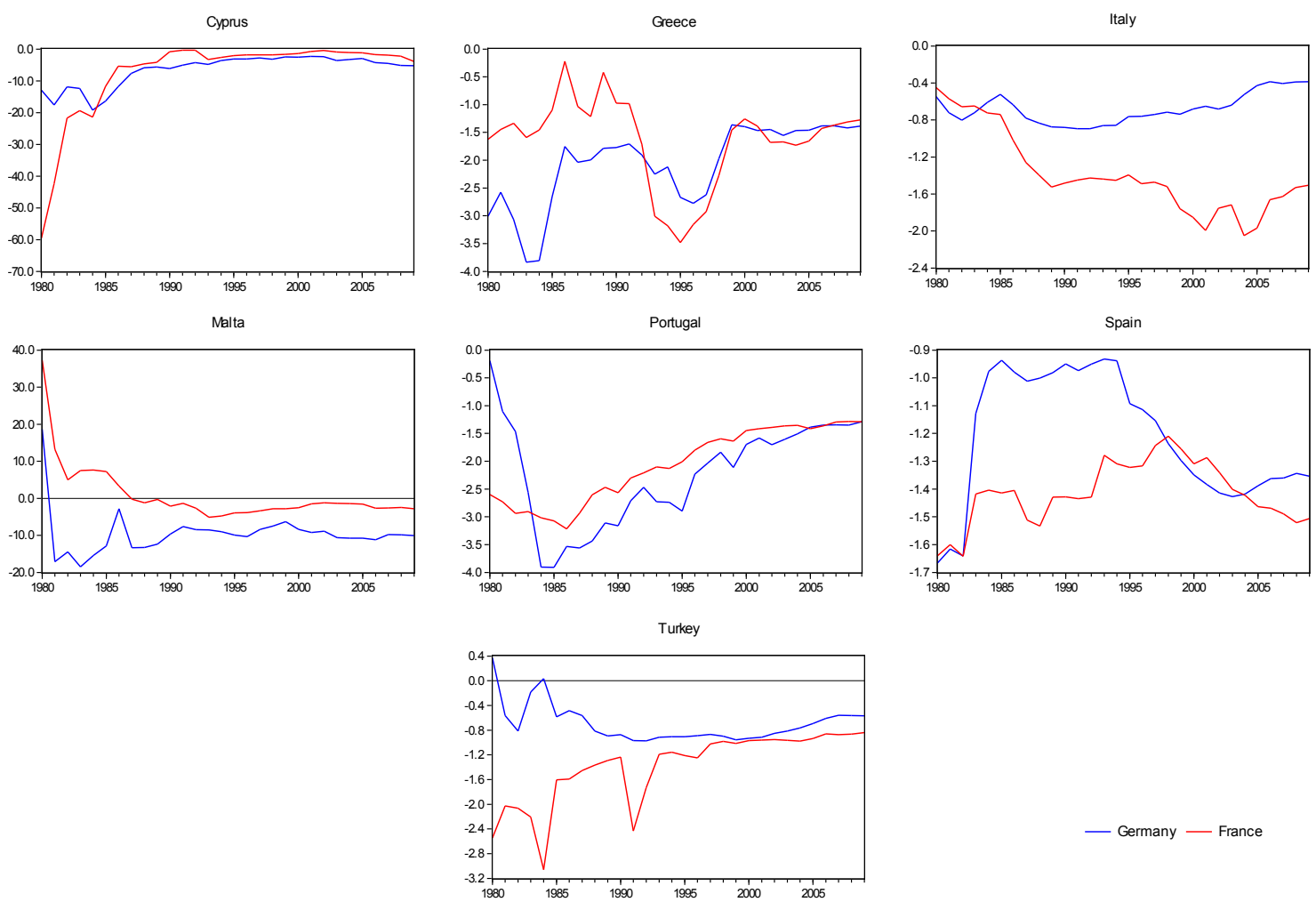

Figure 7. Recursive estimates - own-price elasticities 

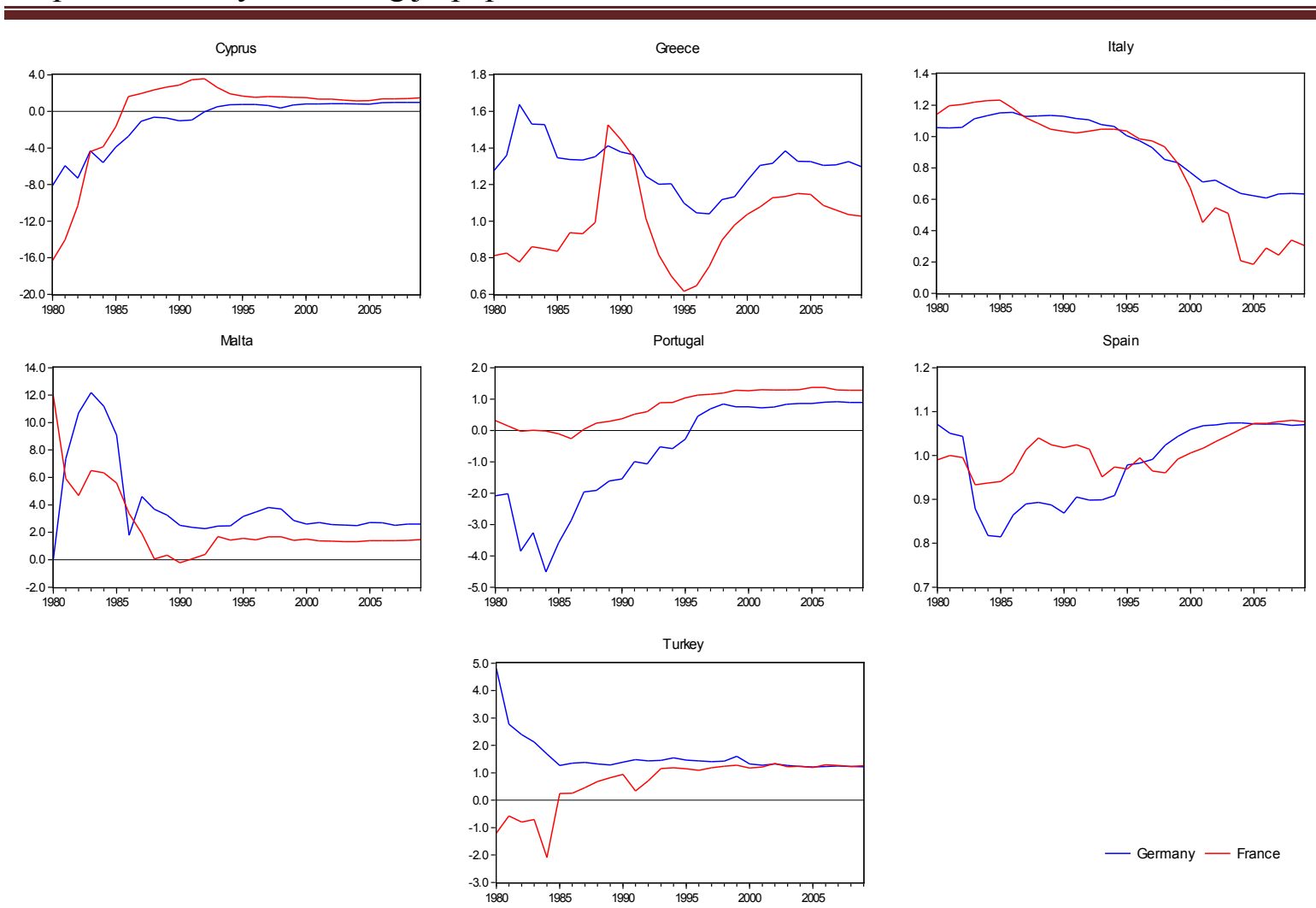

Figure 8. Recursive estimates - expenditure elasticities

In this regard while there is no clear pattern for expenditure elasticities in Greece, the rise in Portugal's expenditure elasticity in both markets, especially in the German market, was remarkable. Price elasticities in Cyprus, Malta and Turkey began a slow ascent from 1990, which could have been a result of favourable movements in relative prices. The general fall in price sensitivity across most of the destinations can also be attributed to the shift in market power from suppliers to tour operators as discussed in section1.3. This analysis demonstrates that testing for rather than assuming away parameter stability is important in applied work.

\section{Conclusions}

The aim of this study is to observe and explain developments in relative French and German tourism market shares across seven major Mediterranean destinations. To this effect we used the AIDS model to estimate tourism demand elasticities for the period 1963-2009. Some of our results can be summarised as follows:

- Spain was a dominant destination in the Mediterranean and was unaffected in price change developments of the other competitor countries.

- Italy lost significant shares in both markets, in part due to consistently higher relative prices, especially after adopting the euro. This made Italy uncompetitive, especially with respect to holidays in countries with expanding tourism sectors like Cyprus, Malta and Turkey.

- A rise in household affluence triggered an increase in tourism expenditure, which translated to more tourists visiting peripheral Mediterranean countries like Turkey and Cyprus. 
- The smallest countries, namely Cyprus and Malta, were particularly sensitive to price and expenditure fluctuations. These countries were able to secure a higher market share over time by reducing their relative prices and at the same time capture part of the increase in real tourism expenditure per capita.

- Turkey gained significant market share, in part due to low relative prices during most of the period. Turkey was also relatively unaffected by developments in other countries.

- While changes in prices across countries did not influence French tourism destinations much, German tourists were particularly sensitive to cross-country price effects.

The results indicate that all countries are regarding as offering "normal" or "luxury" goods as their touristic product since all expenditure elasticities are greater than zero and some are greater than one (Papatheodoru 1999). Meanwhile the own price elasticity estimates are all negative as expected but show considerable heterogeneity between countries. Our most important finding, obtained through the use of recursive estimation of the model, shows that the changes that occurred in the tourism industry since the 1960s had a significant impact on price and expenditure demand elasticities in the destination countries. In this regard formulating policy on the basis of 'average' elasticities can be damaging to the tourism industry. These findings can be utilized by the respective policy making tourism institution in each respective country to steer the macro-economic and price competitive policies to help the respective countries continue to develop their tourism industry in the Mediterranean.

A limitation of our analysis is that it does not shed light on how the elasticities might have been affected by the financial crisis and subsequent recession in Europe, as our sample stops in the beginning of the economic downturn. If elasticities did not change a general fall in expenditure is expected to impact all countries in the same way. Future work could be carried out with the aim of testing this statement.

\section{Acknowledgements}

The authors would like to thank an anonymous referee for valuable comments and suggestions, and express their gratitude to $\mathrm{Dr}$ Andreas Papatheodorou for providing an important share of the historical data used in this study, as well as Dr Alexander Apostolides for providing data for Cyprus. We are also thankful to Mr Leslie Vella, Director of Marketing Support and Development at the Malta Tourism Authority, for invaluable discussions on the evolution of Mediterranean tourism since the 1960s. Thanks are also due to participants of the International Conference on Tourism (ICOT), held in Limassol, Cyprus, in June 2013. The opinions expressed are the authors' own and are not necessarily those of the Central Bank of Malta or the University of Malta. William gratefully acknowledges financial support from the Central Bank of Malta.

\section{References}

[1] Athanasopoulos, G., Deng, M., Li, G., \& Song, H. (2014). Modelling substitution between domestic and outbound tourism in Australia: A system-of-equations approach. Tourism Management, 45, 159-170.

[2] Câmara, B. (2009). The development of the Portuguese hotel business, 1950-1995. In L. Segreto, C. Manera, \& M. Pohl (Eds.), Europe at the Seaside: The economic history of mass tourism in the Mediterranean (pp.72-89). New York, NY: Berghahn Books. 
[3] Cortés-Jiménez, I., Durbarry, R., \& Pulina, M. (2009). Estimation of outbound Italian tourism demand: A monthly dynamic EC-LAIDS model. Tourism economics, 15(3), 547-565.

[4] De Mello, M., Pack, A., \& Sinclair, M. T. (2002). A system of equations model of UK tourism demand in neighbouring countries. Applied Economics, 34(4), 509-521.

[5] Deaton, A., \& Meullbauer, J. (1980). An almost ideal demand system. The American Economic Review, 70(3), 312-326.

[6] Divisekera, S. (2003). A model of demand for international tourism. Annals of tourism research, 30(1), 31-49.

[7] Durbarry, R., \& Sinclair, M. T. (2003). Market shares analysis: The case of French tourism demand. Annals of Tourism Research, 30(4), 927-941.

[8] Hahn, W. F. (1994). Elasticities in AIDS models: comment. American Journal of Agricultural Economics, 76(4), 972-977.

[9] Koike, A., \& Yoshino, D. (2013). Short-run and long-run structural international tourism demand modelling based on dynamic AIDS model - An empirical research in Japan. Proceedings of the Eastern Asia Society for Transportation Studies, 9.

[10] Li, G., Song, H., \& Witt, S. F. (2004). Modelling tourism demand: A dynamic linear AIDS approach. Journal of Travel Research, 43(2), 141-150.

[11] Li, G., Wong, K. K. F.., Song, H., \& Witt, S. F. (2006). Tourism demand forecasting: A time varying parameter error correction model. Journal of Travel Research, 45(2), 175-185.

[12] Lyth, P. (2009). Flying visits: The growth of British air package tours, 1945-1975. In L. Segreto, C. Manera, \& M. Pohl (Eds.), Europe at the Seaside: The economic history of mass tourism in the Mediterranean (pp. 11-30). New York, NY: Berghahn Books.

[13] Manera, C., Segreto, L., \& Pohl, M. (2009). Introduction: The Mediterranean as a tourist destination: past, present and future of the first mass tourism resort area. In L. Segreto, C. Manera, \& M. Pohl (Eds.), Europe at the Seaside: The economic history of mass tourism in the Mediterranean (pp. 1-10). New York, NY: Berghahn Books.

[14] Mangion, M. L., Durbarry, R., \& Sinclair, M. T. (2005). Tourism competitiveness: price and quality. Tourism economics, 11(1), 45-68.

[15] Mangion, M.L., Cooper, C., Cortes-Jimenez, I., \& Durbarry, R. (2012). Measuring the effect of subsidization on tourism demand and destination competitiveness through the AIDS model: An evidence-based approach to tourism policymaking. Tourism Economics, 18(6), 1251-1272

[16] Papatheodorou, A. (1999). The demand for international tourism in the Mediterranean region. Applied Economics, 31(5), 619-630.

[17] Sharpley, R. (2003). Tourism, modernisation and development on the island of Cyprus: challenges and policy responses. Journal of Sustainable Tourism, 11(2-3), 246-265.

[18] Song, H., \& Li, G. (2008). Tourism demand modelling and forecasting - A review of recent research. Tourism Management, 29(2), 203-220

[19] Stone, J. R. N. (1954). The measurement of consumers' expenditure and behaviour in the United Kingdom, 1920-1938 (Volume 1). Cambridge University Press. 
[20] Syriopoulos, T. C., \& Sinclair, M. T. (1993). An econometric study of tourism demand: the AIDS model of US and European tourism in Mediterranean countries. Applied Economics, 25(2), 1541-1552.

\section{Copyrights}

Copyright for this article is retained by the author(s), with first publication rights granted to the journal. This is an open-access article distributed under the terms and conditions of the Creative Commons Attribution license.

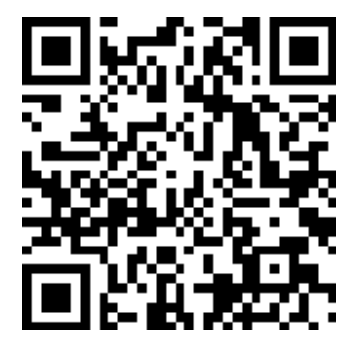

